\title{
Synergistic and antagonistic AML cell type-specific responses to 5-AZA-2'-Deoxycytidine and 1-H-D-Arabinofuranosylcytosine
}

\author{
Abeer Abd Elmoneim ${ }^{1,2,3^{*}}$, Elisabeth Heuston ${ }^{2}$, Daniel H Wai ${ }^{4}$, Timothy Trich ${ }^{5}$, Robert J Arceci ${ }^{2}$ \\ From 2nd International Genomic Medical Conference (IGMC 2013) \\ Jeddah, Kingdom of Saudi Arabia. 24-27 November 2013
}

\section{Background}

The search for synergistic drug combinations is critical to the treatment of drug resistant cancers, such as acute myelogenous leukemia (AML), which has 50\% to $60 \%$ overall survival in children and lower in adults [1]. Conventional treatments include the $\mathrm{S}$ phase-specific polymerase II inhibitor 1-h-D-Arabinofuranosylcytosine (ARA-C), but DNA methyltransferase inhibitors such as 5-Aza-2'-deoxycytidine (DAC) also have activity in AML, through DNA genomic demethylation and altered gene expression [2]. Although genome-wide changes in RNA expression associated with DAC and ARA-C are not fully understood [3], characterizing these responses is a critical step to increasing the efficacy of combinatorial therapies that include DAC and ARA-C.

\section{Materials and methods}

RNA expression levels were assessed using the Human Exon 1.0ST (Affymetrix) array 72 hours after single-dose treatments with $1.0 \mu \mathrm{M}$ DAC or ARA-C in UT7epo, Molm13, and NB4 cells. The half maximal effective concentration (EC50) of DAC and ARA-C was determined in each cell line, and the drug combination index (CI) was calculated using the Chou-Talalay method.

\section{Results}

While increased RRM2 expression is observed following ARA-C exposure and is associated with ARA-C resistance in UT7epo cells, pre-treatment with DAC restores cellular sensitivity and correlates with increased RNA expression of the nucleoside transporter, SLC29A1/hENT1. In contrast, DAC/ARA-C combinations are antagonistic in

\footnotetext{
* Correspondence: abeeraaa6@gmx.de

${ }^{1}$ Paediatric Department, Sohag University, Sohag, Egypt

Full list of author information is available at the end of the article
}

Molm13 cells, where each drug independently increases RNA expression of C-KIT and associated proliferation pathways.

\section{Conclusions}

Pre-treatment with DAC can sensitize ARA-C resistant AML cells, but can increase resistance in ARA-C sensitive AML cells. Possible molecular mechanisms for these results are suggested by the transcriptional response to DAC. These results show that responses to drug combinations are driven by the molecular responses of individual cell types. The results also provide an alternative approach for predicting what combinations, dosing and scheduling of drug delivery should be used to better individualize therapy.

\section{Authors' details}

${ }^{1}$ Paediatric Department, Sohag University, Sohag, Egypt. ${ }^{2}$ Sidney Kimmel Comprehensive Cancer Center (SKCCC) Johns Hopkins University, USA.

${ }^{3}$ Taibah university, Almadinah Almounourah, KSA. ${ }^{4}$ Norris Cancer Center, University of Southern California, USA. ${ }^{5}$ Department of Pathology, Children's Hospital Los Angeles, Los Angeles, CA, USA.

Published: 2 April 2014

\section{References}

1. Claus R, Pfeifer D, Almstedt M, Zucknick M, Hackanson B, Plass C, Lübbert M: Decitabine induces very early in vivo DNA methylation changes in blasts from patients with acute myeloid leukemia. Leuk Res 2013, 37(2):190-6.

2. Soncini $M$, Santoro $F$, Gutierrez $A$, Frigè $G$, Romanenghi $M$, Botrugno $O A$, Pallavicini I, Pelicci P, Di Croce L, Minucci S: The DNA demethylating agent decitabine activates the TRAIL pathway and induces apoptosis in acute myeloid leukemia. Biochim Biophys Acta 2013, 1832(1):114-20.

3. Bug G, Ottmann OG: The DAC system and associations with acute leukemias and myelodysplastic syndromes. Invest New Drugs 2010, 28(Suppl 1):S36-49.

doi:10.1186/1471-2164-15-S2-P28

Cite this article as: Elmoneim et al:: Synergistic and antagonistic AML cell type-specific responses to 5-AZA-2'-Deoxycytidine and 1-H-DArabinofuranosylcytosine. BMC Genomics 2014 15(Suppl 2):P28.

\section{() Biomed Central}

